\title{
Acts of Persuasion in Jane Austen's Novels
}

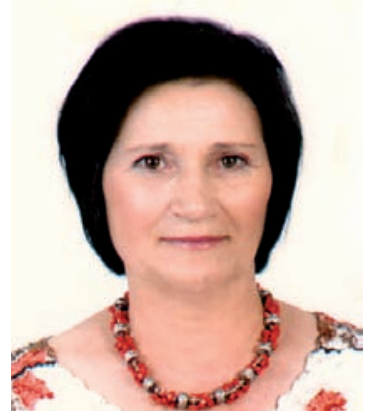

Svetlana Galstyan

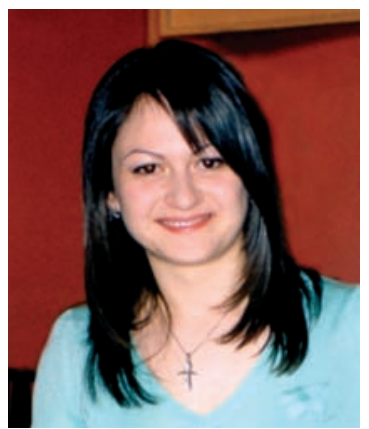

Siranoush Ghaltakhchyan

$\mathrm{T}$ he act of persuasion has been the concern of a vast number of psychologists and linguists who have attempted to discover the peculiar features and the necessary conditions for its effectiveness. It is defined as a conscious, intended attempt of an individual to change the attitude, belief or behaviour of another individual or a group of individuals through the transmission of some message ${ }^{1}$. Whenever there is some change in favour of the message, the process of persuasion can be viewed as successful. Both attitudes and beliefs are non-observable cognitive states, and we make inferences about an individual's attitudes and beliefs from the verbal statements or overt behaviour. Attitudes and beliefs reflect the psychological processes going on in an individual. On the other hand, behaviour changes, including changes in the nervous system, and verbal statements are easily observable and overt. Moreover, getting an individual to admit somebody's attitude or belief is far easier than making the same individual change his behaviour (Scheidel, 1985).

The present article is an attempt to give an insight into Jane Austen's characters in the light of persuasion in Jane Austen's four major novels: "Mansfield Park", "Emma", "Pride and Prejudice" and "Persuasion". Once Virginia Wolf wrote about Jane Austen "Of all great writers, Jane Austen is the most difficult to catch in the act of her greatness. Not to like Jane Austen is to put ourselves under suspicion of a general personal inadequacy and even - let us face it - of a want of breeding" (Trilling, 1965:29). The study of Jane Austen's novels can be viewed as a discovery of universal truths about human nature and life, of 'the supremely civilizing pursuits, the spiritual essence of the social formation' (Modern Science and Vedic Science, 1989:326). Indeed, our investigation has shown that the interpretation of the characters' persuasive communication in Jane Austen's novels can not only give us an account of the fact how certain characters in the novels impose persuasion upon the others but also lead us to a broader comprehension of the communicator's, as well as the recipient's inner being, his/her essence.

As in real life, every character in the novels has his/her unique way of persuading. Some of them prefer to be straightforward while speaking and command their wish explicitly, letting the interlocutors obviously realise their communicative intent. In such instances the act of persuasion may be synonymous to such directive acts as informing, 
directing, instructing, urging, forcing, etc. The character that resorts vividly to this type of persuasion is Mrs. Norris in the novel "Mansfield Park", a boring woman who is fond of interfering with the personal matters of other people, Lady Catherine, a proud woman of dictatorial and insolent manners, and Mrs. Bennet, a middle-class woman of awfully tiresome character in the novel "Pride and Prejudice". Their speeches abound in persuasive attempts, and it is hardly possible to find any dialogue in which they do not have the intention of influencing their interlocutors. On the other hand, they are hardly liable to any influence themselves as they are convinced of their 'truthfulness'. In Mrs. Norris's case, for instance, the desire to persuade and direct people around her reaches such an extent that Mrs. Norris goes beyond the limits of politeness and does not avoid uttering the word "persuade". Moreover, she uses the word with great pride, praising herself and magnifying her endeavour. However, explicit persuasion, as a rule, decreases the effectiveness of a persuasive message greatly and the source's persuasive intent, in this case, often falls flat. It has also been proved that foreknowledge may reduce the chances to succeed in persuasion. ${ }^{2}$

On the other hand, most of the characters tend to choose the implicit way of convincing, especially when an attempt is made by the source to measure and alter the recipient's attitude, belief or behaviour, disguising his/her real intention. Obviously, it is only in the context of the speech act that implicit forms of persuasive communication are revealed. This kind of persuasion is displayed in the characters of Emma Woodhouse and Mr. Knightly in the novel "Emma", Mrs. Darcy in the novel "Pride and Prejudice" and Lady Russell in the novel "Persuasion". They, too, often try to change their interlocutors' initial attitudes and beliefs, but unlike the first group of characters, they make use of various devices while performing persuasive acts. They pretend to be giving information or recommendation, just praising or complimenting, encouraging or advising. This is a more effective way of persuading, and the source, in this case, generally succeeds in persuading the other party.

In the 1940s research was undertaken under the leadership of C. Hovland, entitled 'Yale Communication and Attitude Change Program' to answer many questions on the field of persuasive communication (Byrne, 1981). One of the most precious findings of this program is that there exist two major elements in the target individual's evaluation of a communicator. These are the communicator's credibility and the communicator's attractiveness to the target individual.

Credibility is a set of perceptions about the source held by the recipient. A person's credibility depends on how much expertise the addresser has on the topic under discussion and whether he appears trustworthy and unbiased. Hovland and his colleagues find that high-credibility communicators may be more effective in producing attitude change than low-credibility communicators. They also highlight the idea that the higher a person's evaluation of the communicator (source) is, the more he is likely to be persuaded by the communication. Of interest in this respect is also the observation made by the American psychologist Kelly Shaver: "If someone you evaluate highly is 'at variance' with your current attitude, a 'dissonance' is set up that can be reduced either 
by changing your evaluation of the communicator or by changing your own attitudes" (Shaver, 1977).

In the novel "Persuasion" the protagonist of the novel, Anne Elliot, a young and witty girl with 'an elegance of mind' and 'sweetness of character', is persuaded by her friend Lady Russell to break off her engagement with the man Anne is deeply in love with. Here we face a dilemma, for it is a well known fact that with a clever addressee the communicator's chances to achieve success in a persuasive attempt are very rare, for the more intelligent the addressee is, the less submissive he/she will be because of his/her 'greater critical faculties' (Bettinghaus, 1980). The only reason for Lady Russell's success is perhaps the fact that she always treats her like a considerate mother who is always ready to be of help. Anne is sure that Lady Russell is more experienced and clever and always trusts her. Thus, Anne's love toward Lady Russell has blinded her in this sense. Besides, Lady Russell's persuasive attempts are solely predetermined. She prefers to reach an effect with the so-called 'sleeper effect', i.e. she tends to produce attitude change in a longer period of time and not just immediately after the delivery of the persuasive message in order to make persuasion clandestine (Shaver, 1977).

Kelly Shaver notes, in this respect, that people will consider you credible if you know what you are talking about and if they think that, you have nothing to gain personally by advocating the position you take (Shaver, 1977). She agrees with Hovland's suggested opinion, according to which, a communicator's credibility will be damaged if it is known that he is attempting to persuade a person or a group of people since they might then be suspicious that the communication is biased and even dishonest. This can be best illustrated if we analyse the dialogue between Lady Catherine and Elizabeth in the novel "Pride and Prejudice", where the lady tries to persuade Elizabeth, a girl of 'virtue and wit' and an independent person who remains true to her principles, not to marry Mr. Darcy. Lady Catherine's speech sounds much more like an order than an attempt of persuasion as it is deprived of endearments of any kind that would soften her tone somehow, and not a single attempt of manipulating with words is made. Lady Catherine obviously wants to make Elizabeth realise that she is being persuaded to reject the proposal of marriage and expects immediate submissiveness on the part of the girl, who is much younger and still much inferior in rank. Elizabeth, in her turn, shows reactance $^{3}$ as she does not like when her personal freedom is violated or limited. This is already a good reason to fail. Apart from this, Elizabeth is well aware that Lady Russell has something to gain from this: she wants Mr. Darcy to marry her own daughter.

The other important factor in the recipient's evaluation of a communicator is the communicator's attractiveness to the recipient, the degree to which he/she is liked by the target individual. People often seek to identify themselves with or to be like people for whom they care or admire, which leads them to adopt the admired person's beliefs and attitudes. Hence, the better the source's physical appearance, style of speaking and dressing, gestural and postural systems are, the more persuasive he may be. The character who manipulates with her attractive appearance and good manners in order to 
succeed in imposing persuasion upon others is the protagonist of the novel "Emma", a beautiful and clever woman with 'a comfortable home and happy disposition'. Emma is especially eager to have an influence on Harriet Smith, 'the most gullible, naive and impressionable girl of no social status and connections'. Harriet always underestimates her abilities and finds herself too weak and unsophisticated to solve any problem all by herself. Therefore, Emma does not lose the good chance and considers it necessary to instruct her how to think and reason in the right way. Harriet, in her turn, treats Emma as an ideal of beauty and intelligence. She has assured herself that Emma is the one who can show her the right way of living and has 'put' her life in Emma's hands. In addition to this, Harriet completely lacks self-esteem. People with low self-esteem, ${ }^{4}$ like Harriet Smith, appear to be less confident, less optimistic, less competent, regard themselves as less capable and are less happy than people with high self-esteem. Consequently, such people are, as a rule, more persuadable. Harriet always consults Emma before making decisions or taking a position on a certain topic, even on very intimate matters, such as marriage.

The second vital factor in persuasive communication is message content. Plato regarded persuasion as the key to power and message as the key to persuasion. There are certain factors that influence the effectiveness of messages. Hovland and his fellow researchers assume that for a message to be persuasive, it must first of all be attended to and comprehended. The style and structure of message may provide good incentives for attitude change if they are chosen carefully and in accordance with the topic. It has been proved that communicators who use powerful style of speaking are likely to be more persuasive (Bettionghaus, 1980). Moreover, people are more apt to be persuasive if a message is delivered at a normal rate of speed. This is the reason why Mrs. Bennet in the novel "Pride and Prejudice" almost always fails in persuasive attempts. She frequently makes use of hesitation markers and hedges, such as 'well', 'hmm', 'kind of', 'so', etc. and almost always speaks too fast and with an unconfident tone of voice.

It is a well-known fact that alongside the verbal code system, i.e. language, all of us use the non-verbal code system, in other words, body language, i.e. head nodding, shoulder shrugging, smiles, frowns, etc., to accompany our speech. However, when accompanied with linguistic cues, non-verbal cues should correspond to the verbal message being transmitted. Otherwise, the recipient may be misled and this may obstruct the proper comprehension of the message. Such a phenomenon is observed in the character of Mr. Collins, a heavy-looking young man, in the novel "Pride and Prejudice" when he tries to get Elizabeth's acceptance of his proposal of marriage. His speech does not correspond to the demands of the situation. It is performed, however strange as it may sound, in a very formal and even indifferent manner, with a confident tone of voice. Besides, he begins to speak about quite unnecessary matters, such as why he should get married, how eager his aunt is to see him married and the like. Thus, a 'discrepancy' occurs between Mr. Collins and Elizabeth which is named 'nonverbal leakage', i.e. the verbal and non-verbal message counteract each other (Byrne, 1981). It should be noted here that for successful persuasive communication the source should be able to predict 
how the recipient will understand his verbal, as well as non-verbal behaviour and manipulate with them accordingly. The communicator should know how and what to utter in the specific context to get the wanted perlocutionary effect. Therefore, Mr. Collins's failure in this case is inevitable.

In the process of persuasion a special and final role belongs to the recipient. It is more than apparent that not all attempts to achieve persuasion can be successful in human interaction, and not always do recipients yield to the persuasive message. In many cases failure or success in persuasive communication is dependant upon the recipient of the message. A question arises here. Are certain people more inclined to persuasion than others? J. W. Zanden notes that there are two main kinds of people. "Some people are 'gullible pushovers', while others stubbornly 'stick to their guns' (Zanden, 1977).

乃kolnick and Keslin suggest that individuals high in their "need for social approval", i.e. the desire to be liked by others, are easier to influence than persons lower in this need (as cited in Shaver, 1977). This is, perhaps, the basic reason why Miss. Crawford in the novel "Mansfield Park" easily yields to the persuasive attempts made by any members of the Bertram family, who are much higher in their social status. Miss. Crawford has laid her eyes on Edmund Bertram, the elder son of the family, and does her utmost in order to be loved and admired by him. She has created a picture of a submissive woman and always agrees to whatever he says or pretends as if she judges and reasons the same way as Edmund does.

To conclude, it is worth noting that persuasive communication appears to be a kind of dishonest act in Jane Austen's works, for it violates, to a certain extent, the interlocutor's freedom of thinking and reasoning, and it is often of a biased nature. This is not merely our subjective observation. As we see, Jane Austen herself ascribes the act of persuasion to the characters having a lower level of intelligence and a lower state of consciousness. Surprisingly, in our real life persuasion is also viewed to be a kind of negative act. People generally do not use the word performatively, in other words, they never say 'I persuade you to...', for the form itself is rather impolite and sounds rude. On the contrary, the expression 'I do not persuade you' is very often used.

\section{Notes:}

1. See: Bettinghaus P. Erwin Persuasive Communication. USA: Holt, Rinehart \& Winston, 1980; Larson C.U. Persuasion: Reception and Responsibility. Wardsworth Publishing Company, 1988; Petty E. Richard \& Cacioppo T. John. Attitude and Persuasion. Classic and Contemporary Approaches. USA, 1981; Zanden W. Wander. Social Psychology. New York, 1977.

2. Foreknowledge refers to the prior knowledge of the persuasive intent. On many occasions, when people receive a persuasive message, they know for sure or, at least, predict that it is designed to alter their views. In these cases, people are less likely to be affected by the persuasive message than if they do not possess such 
knowledge. Besides, forewarning may also give people more time to recall relevant facts and information from memory, facts that may prove useful in rejecting a persuasive message (Bettinghaus, 1980).

3. "Reactance" means protecting our personal freedom. This term refers to the unpleasant, negative reaction we experience when we feel that someone is trying to limit our personal freedom. This, consequently, results in negative attitude change. Moreover, when this threat to our freedom is direct and/or explicit, the resistance increases and reaches the highest degree (Zanden, 1977).

4. Self-esteem refers to the value, worth or regard one places on oneself. Richard E. Petty suggests the importance of self-esteem in persuasive communication, which is positively related to intelligence. He highlights the following idea: "What you think of yourself will depend upon the degree to which your actual successes coincide with the goals and aspirations you have set for yourself' (Petty, 1981:56). People with low self-esteem are, as a rule, pessimistic and unhappier than people with high self-esteem, who "face the world with good impressions of themselves".

\section{References:}

1. Bettinghaus P. Erwin. Persuasive Communication. Third Edition, USA: Holt, Rinehart \& Winston, 1980.

2. Byrne Donn. Social Psychology: Understanding Human Interaction. Third Edition, New York, 1981.

3. Grice H. P. Logic and Conversation. Vol 3, New York, 1975.

4. Houston H. Susan. A Survey of Psycholinguistics. Mouton, 1972.

5. Larson C.U. Persuasion: Reception and Responsibility. Fourth Edition, Wardsworth Publishing Company, 1988.

6. Modern Science and Vedic Science. An Interdisciplinary Journal Devoted to Research on the United Field of All the Laws of Nature, Fairfield, Iowa: MIU, 1989. Vol. 1, No. 3.

7. Petty E. Richard; Cacioppo, T. John. Attitude and Persuasion. Classic and Contemporary Approaches. USA, 1981.

8. Shaver G. Kelly. Principles of Social Psychology. Cambridge, 1977.

9. Trilling Lionel. Beyond Culture: Essays on Literature and Learning, New York, 1965.

10. Zanden James W. Wander. Social Psychology. New York, 1977.

\section{Sources of Data:}

1. Austen, Jane. Mansfield Park. London: Penguin Group, 1992.

2. Austen, Jane. Emma. London: Penguin Group, 1996.

3. Austen, Jane. Persuasion. London: Penguin Group, 1994.

4. Austen, Jane. Pride and Prejudice. London: Penguin Group, 1992. 


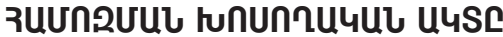

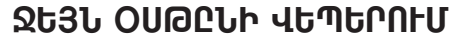

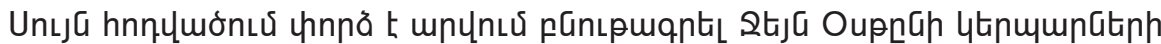

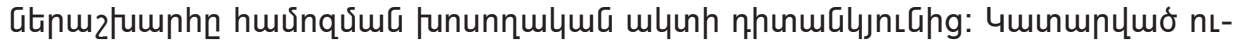

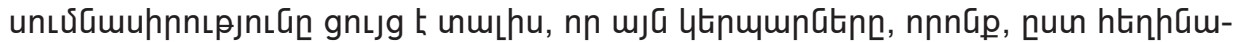

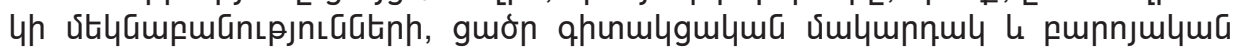

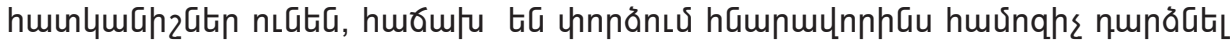

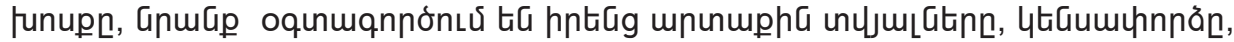

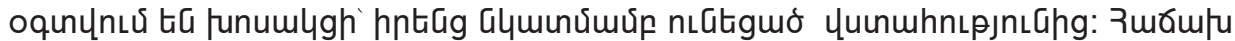

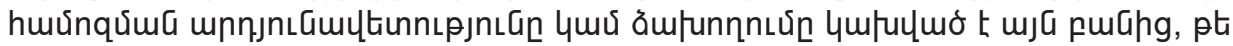

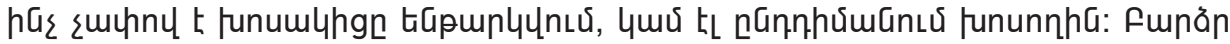

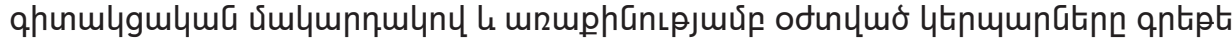

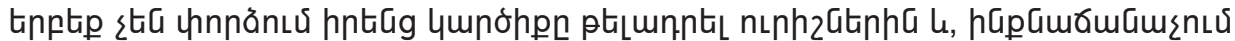

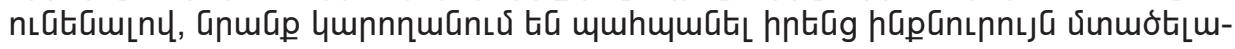

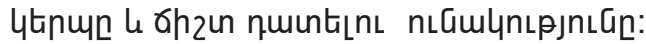

